\section{ELIPSES Y PARÁBOLAS \\ DE LA EXPERIENCIA. \\ LA OBRA DE FRANZ KAFKA SEGÚN WALTER BENJAMIN}

\author{
Daniel García Roldán \\ Profesional en Estudios Literarios de la Universidad Javeriana \\ y Maestro en Historia y Teoría del Arte y la Arquitectura de la \\ Universidad Nacional de Colombia \\ dagarro77@hotmail.com
}

\begin{abstract}
Kafka's work is defined by Benjamin as encompassing both sides of the notion of experience; mystical tradition and the experience of modernity. This essay looks at that idea, and explores the historical, social and intellectual relationships between both authors.
\end{abstract}

KEY WORDS: Experience; tradition; modernity; judaism; literature.

\section{ENTRE EL COMENTARIO Y LA CRÍtICA}

En una de las últimas cartas que envió a Gershom Scholem, en medio de la desesperación debido a los caminos que se cerraban a cada paso y ante la inminente necesidad de abandonar Europa, Walter Benjamin escribió su último juicio sobre la obra y la figura de Kafka: la clave de su interpretación consistía en comprender el humor que las colmaba. No porque Kafka fuera un humorista, expresa a Scholem en la carta, sino por haber tenido que soportar el destino de estar rodeado de payasos. Tal afirmación está marcada por un tono de certeza sorprendente. Pareciera incluso que para pronunciarla Benjamin hubiera tenido que encarnar el fantasma del escritor, recorrer sus pasos; sin duda lo hizo. Los lazos que los unían no eran pocos. El destino cómico y absurdo de los héroes kafkianos terminó por asemejarse al suyo propio.

Éste el motivo por el cual las páginas que Benjamin dedicó a Kafka están más próximas al comentario que a la crítica. Con este término de lo que se quiere dar cuenta es de una cercanía entre el pensador y su objeto de estudio. Cercanía que se hace tan intensa en algunos momentos que los roles

\section{ELLIPSES AND PARABOLAS OF THE EXPERIENCE. KAFKA'S WORK VERSUS WALTER BENJAMIN}

RESUMEN: Walter Benjamin define la obra de Franz Kafka como una elipse cuyos focos son la experiencia de la tradición mística y la experiencia de la modernidad. En el siguiente ensayo se dilucida esta interpretación de Benjamin y se exploran las correspondencias históricas, sociales e intelectuales existentes entre ambos autores.

PALABRAS CLAVE: Experiencia; tradición; modernidad; judaísmo; literatura.

parecen invertirse (no está de más pensar la posibilidad de hacer una lectura crítica de la obra de Benjamin a partir del lente kafkiano). El título del único ensayo sobre Kafka -En el décimo aniversario de su muerte- escrito por Benjamin en 1934 hace patente una realidad temporal común; tan sólo 16 años transcurrieron entre la muerte del escritor y la del filósofo'. Sin embargo no es éste el único lazo (ni el más fuerte); ambos fueron judíos occidentales y compartieron una relación desarraigada e intima con la lengua alemana: una patria (literaria y filosófica) y una exclusión común (antisemitismo). Los héroes de Kafka pierden su nombre, tal como Benjamin tuvo que hacerlo para publicar sus trabajos en Die Frankfurten Zeitung ${ }^{2}$. Ambos estuvieron marcados por el signo del fracaso -Benjamin afirma que para "... hacer justicia a la figura de Kafka en su pureza y en su belleza particulares, no se debe perder de vista..." "... que fue un fracasado"- y sus célebres biografías son testimonio de una fuga incompleta y de la libertad que no se conquista. El filósofo se quitó la vida por ver fallido su intento de huida a América cuando era claro que en Europa no había para él un lugar distinto a un campo de concentración. El escritor consumió la suya en una obra a la que aparentemente tituló Tentativas de evasión fuera 
de la esfera paterna. No sobra recordar lo inacabado e intervenido de ambas obras. La de Kafka por parte de Max Brod, quien estuvo encargado de las primeras ediciones de sus novelas. Un caso similar de intervención y organización ocurrió con gran parte de la obra de Benjamin que fue publicada después de su muerte.

Es necesario reconocer estas correspondencias para darle sentido al término comentario. Una serie de temas que marcaron la producción de Benjamin aparece en las novelas de Kafka como un rumor insistente. Algunos conceptos y nociones claves de la obra del filósofo se ponen en escena, atomizados, ridiculizados y prácticamente desechos en la prosa kafkiana ${ }^{3}$. Benjamin está al tanto de la situación y como si la obra del escritor (o más grave aún, la suya propia) fuera a desaparecer con la catástrofe, la cita largamente en su ensayo de 1934. Es cierto que citar y montar son dos técnicas básicas que Benjamin emplea para tejer su pensamiento y convertirlo en texto; pero en el caso de Franz Kafka: en el décimo aniversario de su muerte hay algo más que eso.

En los trabajos que Benjamin dedicó a Baudelaire, Lesskow o Brecht, el autor criticado nunca habla de manera tan insistente y si cabe el término, necia. Por el contrario, en este ensayo Kafka "narra" largos fragmentos de su obra que Benjamin entrelaza con breves frases de su autoría ${ }^{4}$. En otras partes del ensayo la escritura parece hecha de escombros, robos que le hace el filósofo (aún vivo) al escritor (ya muerto). Sin duda la dificultad que se experimenta en la lectura de este texto está determinada por otra anterior que se dio en su escritura. ¿Cómo interpretar esa complejidad? En Franz Kafka: en el décimo aniversario de su muerte parece desplegarse de manera implícita un diálogo entre Kafka y Benjamin. Diálogo que hace visible un pensamiento dialéctico, pero también un juego; en el ensayo aparecen imágenes y nociones que se entrelazan, se abren (es decir, se explican) y luego se repliegan sobre sí mismas sin haber aportado un sentido claro al lector. En ocasiones incluso pareciera que se trata del rumor de unas voces. El mismo Benjamin le escribirá años más tarde a Scholem sobre este trabajo: "me embarga sobre todo el rasgo fundamentalmente apologético que le es inherente" (Benjamin, 1980: 208).

Por otra parte, las cartas que Benjamin escribió sobre la obra de Kafka cuatro años más tarde se acercan más a un trabajo crítico ortodoxo. Sin embargo, al ser escritos epistolares no se pierde del todo ese carácter de comentario que el filósofo hace del escritor. A diferencia del ensayo, aparecen muy pocas citas de la obra. Las cartas son unos ejercicios de síntesis que en algunos pasajes, debido a su concisión, resultan cripticos. Por ello es necesario tener en cuenta el primer material elaborado para aclararlas, además de otros textos no directamente relacionados con Kafka. Aun así, no deja de ser difícil la lectura y esto sin duda tiene con ver con el hecho de que "Benjamin interpretó a Kafka luchando con él. En 1931, confiesa que hay en Kafka cosas que provocan en él una resistencia tan grande como 'grande ha sido el tormento físico de su lectura'" (Benjamin, 1980: 221).

Reflexionar sobre la noción de experiencia que Benjamin encuentra en la obra de Kafka es una forma de volver a dibujar con pocos trazos esa cercanía, o mejor, esa lucha del filósofo y el escritor. En ello radica la fuerza de la visión (incluso la previsión) que las páginas kafkianas le dieron a Benjamin para, desde ellas, auscultar el panorama del tiempo que se abalanzaba. En la carta de la que se ocupa este ensayo (enviada a Gerard Scholem el 12 de junio de 1938) se despliega lo que de manera retrospectiva se podría definir como la capacidad admonitoria de los escritos de Benjamin. El filósofo recorta imágenes de la obra del escritor y las sobrepone en la realidad de su época; lo que atisba a partir de tal ejercicio es la silueta de dos significativos crimenes de guerra que cerrarían la primera mitad del siglo $X X$, pocos años después de su muerte: los asesinatos masivos en los campos de concentración y la bomba atómica.

En esta carta, a manera de aviso para la población civil, Benjamin afirma que la experiencia de Kafka como hombre privado deberían adquirirla "las grandes masas como la de su propia abolición" (ibíd.: 206); de igual forma, luego de señalar una extraña pero indudable semejanza entre la prosa kafkiana (particularmente el relato Ante la ley) y una aporía de Arthur Eddington sobre la imagen del mundo que tiene la física cuántica, advierte el papel determinante que tiene esta ciencia en el desarrollo de la técnica bélica (finalmente Hiroshima y Nagasaki serian los acontecimientos que pondrían fin la guerra). Es importante no trivializar estos indicios; es decir, no se trata de caracterizar a Kafka o a Benjamin como profetas de su tiempo. Antes bien, lo que se quiere exponer es cómo en su experiencia del mundo 
ya eran perceptibles los rasgos destructivos de una cultura que cada vez se hacen más evidentes.

\section{EXPERIENCIA}

La reflexión sobre la experiencia (Erfahrung) como el conocimiento que se adquiere con el tiempo y luego se transmite en la palabra forma una de las constelaciones más inquietantes en la obra y la vida de Benjamin. Desde su juventud estuvo preocupado por la entrada de la infancia en el saber adulto, la enseñanza de la moral y el papel de la comunidad estudiantil entregada a la embriaguez antes de que llegaran los "... años de compromisos pobres de ideas y carentes de inspiración..." (Benjamin, 1989: 41). Escrito a los veintiún años en el tono revolucionario y libertario de los manifiestos de las vanguardias artísticas que aparecieron publicados en la misma época, Experiencia (1913) es un breve texto en el que Benjamin se lanza al ataque contra la generación de los padres. Al igual que Kafka, quien un año antes había escrito La Condena, y que toda una generación de jóvenes judíos asimilados a la cultura alemana, el mundo burgués de los adultos dejaba un legado que no era fácil de heredar. La historia demostraría pocos años más tarde que la desesperación de los hijos frente a tal legado no era infundada: "... ni los padres, ni las madres consideraban al germanismo y al judaísmo como aspiraciones incompatibles $y$, todavía menos, como fuerzas enemigas... (Robert, 1993: 59)"; "... alentaban al primero y querían seriamente conservar al segundo, sin sospechar que el judaísmo tarde o temprano pagaría los gastos de la operación (ibíd.: 60)". En el caso de la obra de Kafka, la resistencia y el rechazo frente a lo apremiante y a la vez absurdo de la acción eficaz ${ }^{5}$ que se exigía sin un fundamento diferente al bienestar, dotaron a ese mundo de la burguesía -la carrera, los negocios, el matrimonio y la familia- de rasgos aterradores. En La condena, Kafka dibuja a un padre siniestro que sentencia a muerte a su hijo, justo antes de que éste dé el paso al mundo adulto. La consigna de los padres se convertía así, tanto en Kafka como en Benjamin, en una herencia nefasta. Esto anota el filósofo en su texto Experiencia:

"Libramos nuestra lucha por la responsabilidad contra un enmascarado. La máscara del adulto se Ilama 'experiencia'. Es inexpresiva, impenetrable, siempre igual; ese adulto ya lo ha experimentado todo: la juventud, los ideales, las esperanzas, la mujer. Todo era ilusión. A menudo nos sentimos intimidados o amargados. Quizás ese adulto tenga razón ¿Qué podemos contestarle? Nosotros aún no hemos experimentado nada" (Benjamin, 1989: 41).

Para Benjamin, aun joven, la experiencia en manos del adulto no era otra cosa que un evangelio negativo. "El burgués hace su 'experiencia' y es la eterna y única experiencia de la falta de espíritu" (ibíd.: 43). Esa carencia que el filósofo encuentra y que juzga fundamental para caracterizar al adulto al que se enfrentaba, se puede explicar con las mismas palabras con las que Marthe Robert explica el mundo de los pacíficos comerciantes de la Praga de Kafka, que no podían darse el lujo de tener opiniones, porque literalmente estaban "... sin fe ni ley, o más exactamente, sin más ley que el interés de sus negocios, sin más fe que lo que necesitaban para sobrevivir protegiendo $y$, si es posible, acrecentando la comodidad y la riqueza que difícilmente habían ganado" (Robert, 1993: 78). Si bien es cierto que Benjamin reconoce esta situación como una realidad ["Su creencia (la del adulto) se ha confirmado: es verdad que el espíritu no existe" (Benjamin, 1989: 43)], el idealismo de la juventud en que se formaba su pensamiento reafirmaba una experiencia nueva, distinta, que paradójicamente convertía en su contenido real la insaciable y difícil búsqueda de lo no experimentable -la verdad y la fidelidad-:

\section{"Repito: nosotros conocemos otra experiencia. Esa experien- cia puede ser hostil al espíritu y destruir muchos sueños; no obstante es lo más hermoso, lo más intocable, lo más inmediato, porque jamás puede faltar el espíritu si nosotros seguimos siendo jóvenes" (ibíd.: 43).}

Con el tiempo tanto Benjamin como Kafka tomarian distancia frente a la violencia de su rebelión y a la radicalidad de sus señalamientos de juventud. En un lapso corto, tan sólo siete años separan La condena (1912) de la Carta al padre (1919), el escritor transformó lo que inicialmente parecía una tragedia -el padre que condena a su hijo morir ahogado- en una tragicomedia (el padre mismo tampoco había tenido muchas opciones para "respirar"). Deleuze reconoció el humor como el género en el que se debía incluir la epístola y con ella, toda la obra kafkiana. Citando una frase de Kafka tomada de los diálogos entre él y Gustave Janouch recogidos por este último en su libro Conversa- 
ciones con Kafka, Deleuze resignifica esta insurrección al leerla desde la ironía ("La rebelión contra el padre es una comedia, no una tragedia") (Deleuze, Guattari, 1978: 21). La carta más que una queja amarga que Franz dirige a su padre, debe ser leída como una caricatura agrandada, deformada y grotesca del complejo de Edipo (síntoma que no hacía mucho tiempo el psicoanálisis había incluido en su inventario del inconsciente $\left.{ }^{6}\right)$. Los rasgos siniestros de Hermann Kafka, o en palabras de Benjamin, la falta de espíritu del adulto que quiere a toda costa destruir la experiencia de la juventud, no pertenecian verdaderamente a él, sino a una cultura en la que ambos (padre e hijo) estaban inmersos, compartiendo una situación de inocencia y desolación común. Por eso Kafka le advierte a su padre al principio de la carta: "Esta habitual interpretación tuya de las cosas la considero correcta sólo en la medida en que yo también creo que eres completamente inocente de nuestro distanciamiento. Pero de igual manera soy completamente inocente" (Kafka, 1995: 21).

Lo que deja ver Deleuze detrás de ese Edipo deformado que dibuja Kafka es que en la imagen de la familia no es en realidad el padre quien causa terror, ya que el "... triángulo familiar demasiado bien formado no era más que un conductor de cargas de naturaleza muy distinta, que el niño no deja de descubrir por debajo del padre, en la madre, en sí mismo" (Deleuze, 1978: 23). Por ello en la obra de Kafka "... los jueces, inspectores, burócratas, no son sustitutos del padre, más bien el padre es quien condensa todas esas fuerzas a las cuales él mismo se somete y le pide a su hijo que se someta. La familia sólo tiene puertas, en las que tocan desde el principio las 'potencias diabólicas' que se alegran sin medida de poder irrumpir en nosotros" (ibid.). Esto explica que Kafka haya titulado su obra Tentativas de evasión fuera de la esfera paterna, y que en realidad nunca hubiera querido llevar a cabo de manera práctica tal fuga: "Lo que quería era vivir en la esfera -pero excluido-" (Bataille, 1977: 116).

Para el caso de Benjamin, el texto que juega un papel análogo al que desempeña La carta al padre enfrentado a La Condena, es un breve ensayo que apareció en Die Welt in Wort (Praga: 1933) y que lleva como título Experiencia y pobreza. En estas páginas (Benjamin ya contaba con cuarenta y un años en la fecha en que fueron publicadas) su reflexión sobre el mismo tema había dado un giro significativo. Ya no era el adulto el responsable de esa desvalorización de lo vivido. Se trataba de un estado de la cultura, caracterizada por un enorme desarrollo de la técnica, lo que había causado la baja en la "cotización de la experiencia" (Benjamin: 1974: 167). ¿Qué tácticas podian enseñar los combatientes que volvieron con vida de la Primera Guerra Mundial (un conflicto en el que la masa de los ejércitos había sido prácticamente objeto de experimentación de nuevas armas)? En palabras de Benjamin, jamás habian tenido lugar "experiencias tan desmentidas como las estratégicas por la guerra de trincheras, las económicas por la inflación, las corporales por el hambre, las morales por el tirano" (ibíd.: 168). Las narraciones de los viejos relatos ligados a la laboriosidad y a la tierra, a la vida y la muerte, y a todo lo que se transmite de boca a oído, habían perdido por completo su sentido práctico en la sociedad urbana moderna. Lo que el filósofo descubría repasando de manera retrospectiva las primeras décadas del siglo XX era la deshumanización de la cultura y con ella, la del lenguaje, que ahora se movilizaba "... al servicio de la modificación de la realidad" y no al "de su descripción" (ibíd.: 170). Por eso afirma melancólicamente en la introducción de su texto:

\begin{abstract}
"Sabiamos muy bien lo que era la experiencia: los mayores se la habian pasado siempre a los más jóvenes. En términos breves, con la autoridad de la edad, en proverbios; prolijamente, con locuacidad, en historias; a veces como una narración de países extraños, junto a la chimenea, ante hijos y nietos. ¿Pero dónde ha quedado todo eso? ¿Quién encuentra hoy gentes capaces de narrar como es debido?" (ibíd.: 167).
\end{abstract}

Experiencia y pobreza es un texto en el que el carácter dialéctico del pensamiento de Benjamin produce una de las reflexiones más fecundas que haya legado su obra. Por un lado se advierte en él el peligro de que los bienes de la educación se hayan separado por completo de la experiencia; pero por otro lado se hace evidente el nacimiento de una nueva barbarie (alejada del humanismo y de la tradición) que hace de la pobreza de su experiencia un credo necesario para construir en un nuevo mundo; el mundo en el que la técnica asume en la cultura el lugar que antaño había ocupado (con toda su carga amenazante y milagrosa) la naturaleza. Benjamin fue consciente del valor de los pensadores que habian hecho uso de esa pobreza para construir. Einstein, Klee, Brecht y Loos son algunos de los ejemplos que menciona para hacer visible esa nueva forma de la experiencia, cargada de un contenido acorde a los tiempos de lucha que se vivían en todos los órdenes de 
la sociedad. Hacer tabula rasa y emprender la construcción con muy poco era, para Benjamin, la consigna de los nuevos creadores. De hecho, resultaba considerablemente más práctica la primera frase de Brecht en su Libro de lectura para los habitantes de la ciudad ["Borra las huellas" (ibíd.: 171)] que la servidumbre del burgués al mundo asfixiante de objetos (e instrucciones) que componian su interieur ${ }^{7}$, y en el que la más mínima calamidad en el gobierno doméstico adquiria las proporciones del drama de alguien a quien le han "borrado las huellas de sus días sobre esta tierra" (ibíd.). En cualquier caso, Benjamin ya estaba al tanto de la situación, y tenía claro que la nueva humanidad se preparaba a sobrevivir ante la amenaza que representaba su propia cultura.

Es necesario reconocer este cambio en la consideración del problema de la experiencia en el pensamiento de Kafka y de Benjamin, ya que en ambos la transformación del ataque inicial a los adultos en un cuestionamiento más profundo y difícil de sí mismos y de su propia cultura, se debió en gran medida a un redescubrimiento singular de su tradición. Bajo la condición de asimilados, tanto el filósofo como el escritor se acercaron prácticamente como extranjeros a "su religión" y a "su pueblo", y lo que pudieron tomar de ellos fue todo menos un credo o una doctrina firme. En ese sentido, no se trata de inscribir las obras de Kafka y de Benjamin en el judaísmo, sino de ver cómo su pensamiento se apropió de categorías religiosas y de manifestaciones de la cultura popular judia que se convirtieron en herramientas profanas de autorreflexión y en núcleos vivos de inspiración. En el caso de Kafka, su amistad con el actor yidish Yitsjak Lowy le abrió una puerta al teatro popular judío que venía de Europa Oriental, y en el que encontró una serie de imágenes y personajes que poblaron sus novelas. En el caso de Benjamin, su amistad con Scholem fue significativa en el mismo sentido. Con él desarrolló un interés que traía consigo por el estudio de la religión judía que le aportó una serie de intuiciones valiosas a la inclinación teológica de su pensamiento. En ninguno de los dos casos se puede decir que la apropiación de tales legados no fuera problemática; primero porque la distancia frente a la creencia era mayor que la devoción; y segundo porque ni siquiera como estudiosos del judaísmo se destacaron tanto como en su investigación e interpretación insaciable de obras históricas, literarias y filosóficas que consideraron como su verdadera patria. Cuando Benjamin se refiere a los antepasados de Kafka encuentra, además de judíos, alemanes y checos, a chinos, rusos, griegos, españoles, americanos, indios, e incluso podría decirse, a algunos animales y criaturas hibridas. Quizás algo similar podría afirmarse de los antepasados del filósofo, quien valoró con la misma intensidad a "místicos y satíricos, humanistas y líricos, sabios y monomaniacos" (Scholem, 2004: 25). En esto no hay ironía alguna; antes bien, es ahí donde reside la fuerza de sus obras.

\section{UNA ELIPSE ENTRE LA EXPERIENCIA MÍSTICA Y LA moderna: el caso de KafKa según Benjamin}

Benjamin entabló una amistad con Gerard Gershom Scholem desde 1915 y mantuvo con él una correspondencia casi ininterrumpida hasta el año de su muerte en 1940. Fue también con Scholem con quien sostuvo de manera más intensa un diálogo epistolar sobre la obra de Kafka. De hecho, fue gracias a su ayuda que Benjamin pudo publicar su trabajo de 1934 al que se ha hecho alusión en la primera parte de este ensayo, así como también las reflexiones posteriores que hizo sobre Kafka. Para ambos autores resultaba apremiante la lectura, la interpretación y la discusión de los textos kafkianos. De hecho, Scholem como el representante más significativo del estudio de la mistica judía en el siglo XX, no pudo apartarse en su estudio de la Cábala, de la intensa influencia que marcó en él la lectura de Kafka. En palabras de Harold Bloom "nuestra comprensión de la Cabala es kafkiana, como quiera que sea, ya que Kafka influyó profundamente en Gershom Scholem, y nadie podrá superar, en las décadas por venir, la poderosa o creativa lectura equivoca (misreading) de la Cábala realizada por Scholem" (Bloom et al., 1999: 222).

En las páginas iniciales de la carta del 12 de junio de 1938 en la que se expone el problema de la experiencia en Kafka, Benjamin hace una fuerte crítica al libro de Max Brod ${ }^{8}$. Ante todo, los puntos que encuentra débiles en él se deben a un desacuerdo entre la tesis del autor y los medios que emplea para desarrollarla. Brod, en palabras de Benjamin, sostuvo que Kafka recorría el camino de la santidad y que por ello su obra se debía asumir tal como los fieles asumen, sin rebatirla, la verdad de las doctrinas. Esta tesis, que no dejaba de parecerle peligrosa e inquietante a Benjamin, quedaba invalidada por el estilo grandilocuente y ostentoso de Brod. Para el filósofo este libro era una especie de 
hagiografía escrita en lenguaje de novela de folletín y eso era precisamente lo que dejaba claro que Kafka no era un santo y mucho menos Brod un profeta.

Una vez cerrada esta crítica, Benjamin inicia en su carta una reflexión sobre la obra de Kafka definiéndola como una elipse cuyos focos alejados contraponen dos tipos de experiencia: una mistica y otra moderna. La imagen de la elipse es de esencial importancia para Benjamin, no sólo en lo que se refiere a su interpretación de Kafka, sino también en lo concerniente a su propia obra. En una carta a Scholem de 15 de septiembre de 1934, Benjamin reconocía que en el estudio de esta obra se reunían las características necesarias para tejer la encrucijada de su pensamiento. El 17 de octubre del mismo año, en otra carta, le confesaba que no le iba a resultar fácil deshacerse de la reflexión sobre Kafka, tal como lo había hecho con otros autores. En esta oportunidad aparece por primera vez la imagen de un arco, a partir de la cual surgiría posteriormente la figura de la elipse:

\begin{abstract}
"Sigo aún con Kafka, y debo agradecerte tus nuevas observaciones al respecto. Naturalmente, queda por ver si algún día podré tensar el arco lo suficiente como para que la flecha vuele. Mientras que el resto de mis trabajos han encontrado pronto el vocablo con el que me despido de ellos, a éste tendré que dedicarle más tiempo. El porqué lo ilustra la imagen del arco: aquí me enfrento con dos finales, el político y el místico" (Scholem, Benjamin, 1987: 161).
\end{abstract}

La intensidad con que Benjamin se dedicó al estudio de Kafka se prolongó hasta el final de su vida, y se podría afirmar que la imagen de la elipse expuesta en la carta de 1938, implica más que el vuelo de la flecha, la tensión que no se pudo resolver. Por tal motivo la interpretación de esta figura resulta problemática, pues pareciera que el propio autor la eligió para dar cuenta de una encrucijada de la que aparentemente no había salida. Tal situación plantea sin duda un horizonte complejo, pero también permite que se establezcan relaciones al interior de la obra de Benjamin que sólo quedaron sugeridas de manera implícita y que no contaron con el tiempo suficiente para ser desarrolladas. Éste es el caso de la carta sobre Kafka que será abordada a continuación, ya que al ser interpretada a la luz de otros textos de Benjamin (por ejemplo El narrador), arroja sentidos diferentes a los que él mismo expuso, y que sin embargo provienen de su obra.
Cuando Benjamin se refiere al primer foco de la experiencia de Kafka como una experiencia mística, se piensa inicialmente en todo aquello que en la obra del escritor tiene un carácter marcadamente religioso (para el judaísmo). La obsesión que en las páginas kafkianas se despliega en forma de parábola en torno a la interpretación de la ley y la aparición constante de la figura paterna o de entidades dotadas de un poder y una autoridad irrebatibles, fueron dos de los motivos que permitieron que se relacionara a Kafka con la religión judía. A partir de estos temas se desató una corriente interpretativa en clave teológica por parte de una serie de escritores judíos que reflexionaban intensamente sobre el devenir de su religión en ese momento crítico en que el antisemitismo había vuelto a reinar en Europa y el sionismo aparecia como una promesa. Sin embargo Benjamin asumió cada vez con mayor cautela tales temas. En otra de las cartas que envió a Scholem durante la elaboración de su ensayo de 1934, afirmó que consideraba "la firme insistencia de Kafka sobre la ley como el punto muerto de su obra" (ibíd.: 153), queriendo con ello expresar que tal aspecto no lo animaba a un trabajo interpretativo. Esto no implica que haya ignorado tal problema -de hecho dedicó parte de su ensayo a la reflexión sobre la ley en Kafka- sino que se encontraba en la búsqueda de una categoría religiosa más amplia y que diera cuenta al mismo tiempo del vínculo y del desarraigo del escritor con el judaísmo.

Tal fue la razón de la fuerte crítica a la imagen que Brod había elaborado de Kafka, así como el motivo del rechazó de su exégesis judio-realista de El Castillo9. Tal como se ha afirmado, Benjamin veía (y Kafka también lo hizo) con sospecha algunas posturas del sionismo que no reconocian en su verdadera dimensión el problema que el pueblo judío estaba enfrentando. En ese orden de ideas, ¿a partir de qué categoría religiosa y mística se podía pensar a Kafka sin caer en un abismo especulativo en torno a la cavilación sobre el Dios o la ley del judaísmo? En realidad, más que indagar en los contenidos de la religión era necesario pensar la tradición, es decir, el medio en el que estos contenidos se habían transmitido y transformado a través del tiempo. Al reconocer esta categoría como el aspecto religioso y mistico más significativo de la obra de Kafka, Benjamin logró encontrar el punto de encuentro entre ella y su reflexión sobre el problema de la experiencia en la modernidad.

En la medida en que estas reflexiones fueron configuradas por Benjamin a partir de su dialogo epistolar con Scho- 
lem, es necesario reconstruir la forma en que éste último asumió la categoría elegida por el filósofo para hablar de Kafka. En uno de sus libros titulado Conceptos básicos del judaísmo, Scholem expone el tema de manera concisa y clara. La tradición juega un papel fundamental en la historia de las religiones, y de manera especial en el judaísmo. Ligada a la revelación de la ley, que en la religión judía recibe el nombre de Torá escrita (El Pentateuco), la tradición se entendió originalmente como la forma de comunicar el contenido claro de las leyes (prescripciones) que habian sido reveladas por Dios a Moises y que aparecian en los cinco primeros libros de La Biblia. Sin embargo, con el cambio de las circunstancias históricas para el pueblo judio, que desde su origen estuvo marcado por la persecución y el exilio, ésta adquirió un nuevo sentido en el desarrollo de su religión: dejó de ser comunicación de un contenido normativo y pasó a convertirse en interpretación y comentario de los textos sagrados. Este nuevo fenómeno recibió el nombre de Torá oral; transformada en un concepto dogmático e inseparable de la revelación, la nueva naturaleza de la tradición cristalizaría paulatinamente en textos ( $E$ I Talmud es su principal legado) las investigaciones sobre el Pentateuco y otros libros del Antiguo Testamento. Este proceso permitió nuevas lecturas y comentarios en los que, si bien no se descartaba la autoridad y veracidad del sentido inicial de la revelación, se dio paso a un pensamiento polifónico y rico en contradicciones, que hizo de los textos sagrados del judaísmo un campo fértil de reflexión.

Con la entrada posterior de la mística en el judaísmo, se agregó un nuevo sentido a estas categorías. La Cábala, cuyo significado literal es según Scholem "recepción de la tradición", las dotó de un aura esotérica al afirmar que el contenido de lo revelado en la tradición no era otro que el nombre de Dios: "¿Qué puede propiamente revelar Dios y en qué consiste la voz de Dios que les llega a los receptores? Su respuesta [la de los cabalistas] es: nada distinto de sí mismo, puesto que él se convierte en lenguaje y voz" (Scholem, 1998: 88). A partir del surgimiento de tradición mística o Cábala, que remonta históricamente al siglo XII (pero que tiene raíces en tradiciones esotéricas que aparecen desde el siglo $1{ }^{10}{ }^{10}$ y que se mantendrían vivas en la oralidad por casi un milenio) se inició un nuevo rumbo de la tradición, en la que esta aparece dotada de una fuerza, si cabe decirlo, extática, poética y narrativa. En ella penetró el lenguaje del mito, que en cierto sentido era lo que se había excluido en el judaísmo rabínico clásico (sólo concentrado en las prescripciones), y la dimensión oral de la Torá adquirió un significado primordial. En la medida en que para los místicos lo que se revelaba en los textos era el nombre divino (y por lo tanto, como dios, omnipotente e infinito), la tradición se perfiló entonces para ellos como una experiencia de plenitud de sentido, que en cierta medida resultaba inefable e incomunicable. Al respecto, Scholem anota lo siguiente:

"Esta naturaleza amorfa de la experiencia mística, de las Ilamadas 'vivencias místicas' es fundamental en el problema que aquí tratamos. Al mismo tiempo, supone por principio una infinita plasticidad de dicha experiencia en su último grado, dado el caso de que existiera tal grado de desarrollo" (Scholem, 2005: 8).

Tal experiencia, que de hecho siempre se ha presentado cargada de un carácter problemático para la autoridad religiosa ortodoxa (por haber cuestionado en varias oportunidades su fundamento) fue la que llevó al extremo opuesto el sentido inicial y claro de los textos sagrados. Para los místicos, tal como lo expone Scholem, la revelación implicó por un lado la transformación de la Torá en un organismo vivo y con ello la apertura de una infinita multiplicidad de sentidos de la palabra divina (de la ley), y por otro, la intensidad del acto mismo de recibir y poder transmitir, mediante la escritura y en forma oral, esa palabra. Benjamin utilizó esta imagen de la recepción de la tradición por parte de la mística para caracterizar uno de los focos de la experiencia kafkiana, por dos razones. La primera, porque le ayudó a abrirse a una multiplicidad de sentidos que surgían de sus relatos, en los que los grandes temas del pensamiento judío -"... el Exilio, la Culpa, la Expiación o si, se quiere, en términos más modernos, la culpabilidad vinculada al desarraigo y la persecución..." (Robert, 1993: 13)- se ponian en juego; y la segunda, porque le permitió repensar el problema de la crisis de la tradición y la forma de la experiencia en la modernidad.

Sin embargo, y aunque Benjamin practicó la interpretación teológica de la obra de Kafka, lo que quería destacar era precisamente el carácter problemático que tal operación implicaba. Desde el desarrollo de la llustración, a lo largo del siglo XVIII, la fuerza de la cultura secular había relegado a la religiosa, desplazándola de su antiguo papel como autoridad. La Haskalá fue ese proceso al interior del judaísmo, durante el cual se produjo la asimilación de 
una parte significativa del pueblo judío occidental a las nacionalidades, lenguas y costumbres europeas modernas. Por ello no se puede pensar en Kafka sin hacerlo heredero también de la tradición cristiana occidental y de su fuerte proceso de desacralización. Es necesario tener en cuenta (por mencionar tan sólo dos de sus influencias más notables) las reflexiones sobre Dios y la religión que se desarrollaron en obras como las de Dostoievsky o Flaubert (particularmente en Las tentaciones de San Antonio). En ellas tanto el nihilismo como la razón científica entran en conflicto con la tradición y la autoridad religiosas. El baudelaireano culto a Satán y la frase de Nietzsche Dios ha muerto son nítidas manifestaciones de este pensamiento poético-filosófico en gestación que sin duda heredaron Benjamin y Kafka. ¿Cómo resultó posible entonces para el filósofo hablar de una experiencia mística en la obra del escritor?

Para Benjamin, en el caso de Kafka la tradición había llegado a un grado cero, es decir, al punto extremo de no revelar nada. Por eso en sus cartas a Scholem le pregunta por una noción que éste había desarrollado en sus interpretaciones del mismo autor: "Te ruego que me ilustres tu perífrasis de que 'Kafka nos presenta el mundo de la Revelación en una perspectiva en la que se dirige de nuevo a su propia Nada'" (Scholem, Benjamin, 1987: 153). Ante esta inquietud, Scholem respondió lo que se podría considerar como la hipótesis que utilizó Benjamin para reflexionar en torno al problema de la experiencia mística en Kafka. Al parecer, la carencia de sentido también podía entenderse, o mejor, era en su reverso, una experiencia que (tal como la mística) se abría a una infinitud de significados. Scholem, quien luego afirmaría que "... los escritos de Franz Kafka nos presentan los impulsos místicos, por así decir, reducidos al grado cero, y aún en el grado cero mismo, en el que parecen desaparecer, conservan una infinita eficacia..." (Scholem, 2005: 13), respondió esto a la inquietud de Benjamin:

“Preguntas qué entiendo por la 'Nada de la revelación'. Me refiero a un estado en el que ésta aparece vacía de significado, en el que si bien se afirma y es válida, sin embargo no significa. Cuando falta la riqueza de la significación y lo que se manifiesta, reducido a un punto cero de contenido propio, sin embargo no se desvanece (y la revelación es algo que se manifiesta), entonces surge su Nada" (Scholem, Benjamin, 1987: 160).
Esa falta de sentido y la consecuente desacralización de la palabra con que la tradición religiosa se le había revelado a Kafka, definen para Benjamin el otro foco de la elipse que describe la obra kafkiana: la experiencia moderna. Si bien la fuente de donde esta obra abrevó su fuerza fue la tradición, el despliegue de su ingenio y su humor se dan en el vaciamiento de la misma en el mundo moderno. Por eso en los relatos kafkianos el místico aparece encarnado en un galgo. En Las investigaciones de un perro, uno de los últimos cuentos que escribió, el narrador es un perro que en su juventud tuvo una experiencia mística que lo sumió en una reflexión incansable sobre la comunidad perruna y su destino. Este relato es una especie de autobiografía de Kafka como investigador y místico de su tradición y su pueblo. Sin embargo eligió la identidad del perro y no la del profeta como narrador de sus vivencias por varias razones. La primera, para denotar que esa experiencia mística y mágica del lenguaje (en el cuento se trata de una melodía y a la vez de un ruido insoportable que hace danzar misteriosamente a siete perros que se paran en dos patas) era prácticamente opuesta a la forma social de la lengua, utilizada como un instrumento rígido de discriminación, conveniencia y dominación: "El advenimiento del nazismo fue ante todo el de una forma de hablar" (Arántegui, Nordau, 1999: 7). Para la cultura germana del padre de Kafka, los judíos desplazados que venían de Rusia -y que no tenían más posesiones que ellos mismos, su pobreza y el yidish-, resultaban repugnantes. Por eso le advertía a su hijo con un lema popular de su medio: "el que con perros anda, también es perro" (Robert, 1993: 32). Kafka asumió esos insultos como metáforas animadas -después de todo tenían un efecto fuerte sobre él- y en lugar de aceptar la codificación social que le imponian, los utilizó como máscaras de su voz en varios relatos. No sobra recordar la pulsión antisemita que cargaba la lengua alemana y con la que Kafka tuvo que luchar hasta la muerte. Por lo demás, en su caso la batalla era aún más dura, pues parte de sus experiencias más plenas (casi místicas podría decirse), las había vivido con el grupo y las fiestas del teatro de Lowy:

\footnotetext{
"Por más que el teatro yidish pertenezca a un género menor e impuro, no deja de lograr lo que el arte más destacado no siempre puede ufanarse de conseguir: una apertura total del cuerpo y del alma, una unidad casi carnal entre el público y la escena, un instante de olvido de sí en que cada cual se pierde en todos" (ibid.: 89).
} 
Por eso la identidad del perro no es únicamente una máscara. Es también el lugar desde donde el escritor quiere hablar, pues está al tanto de que su situación de desarraigo no es exclusiva de los judíos (Löwy y compañía le demostraban lo contrario), sino una condición del sujeto moderno. Por eso si el Kafka místico narraba, no había una criatura más adecuada que el perro para encarnar su voz. En él se reúnen la sabiduría del silencio junto a un estado de acomodo y resignación ante la cultura como en ningún otro ser: "Ser animal no significaba para él [Kafka] sino haber renunciado por una especie de pudor a la figura y a la sabiduría humanas" (Benjamin, 1980: 207). En todas sus formas posibles (encarnando el animal, el parásito el objeto, el híbrido, la cosa inservible, el recién llegado) las figuras inverosímiles de Kafka se concentran en la imagen de aquel que es un extraño en todos los niveles de la existencia: en su territorio, entre los suyos e incluso en su propio cuerpo. Para el perro místico de Kafka, la única revelación que surge de su experiencia es una pregunta para su pueblo: ¿De dónde saca la tierra su alimento? Ante ella, los otros perros no pueden más que incomodarse, guardar silencio, y decir con afán para callarlo, aunque en realidad no lo cumplan: "Si no tienes suficiente comida, te daremos la nuestra" (Kafka, 2001: 354). Esto empuja al narrador a un ayuno que llega al grado extremo de la agonía. Sin embargo justo antes de morir, la aparición de un sabueso cazador que necesita expulsarlo de allí porque su presencia no lo deja cazar, le revela la música de su experiencia inicial. El ruido lo obliga (fuera de si) a correr en busca de alimento: "Me levanté vacilando, me miré 'éste no saldrá corriendo', pensé, pero inmediatamente emprendí la marcha dando espléndidos saltos, llevado por la melodía" (ibíd.: 375).

Tal experiencia de la tradición es la que Kafka legó; una que sólo revela su verdad en la agonía y que en lugar transmitir el destello de un nombre divino, hereda el lado funesto de todo lo nombrado. En sus novelas, el nombre oculto y sagrado de Dios, que había sido el motivo central de la mística judia, se traduce en la pérdida de derecho al nombre que sufren progresivamente sus protagonistas. El desaparecido Karl Rossman termina llamándose Negro; José $\mathrm{K}$ en $E l$ proceso no tiene apellido y $\mathrm{K}$ (el héroe de $E I$ castillo) no sólo ha perdido por completo este derecho, sino también su lugar en el mundo. En este caso, como anota Marthe Robert, se pasaba del nombre oculto y sagrado al prohibido y maldito, tal como les ocurrió a los judíos que tuvieron la necesidad de camuflar su identidad una vez reanudada la persecución.

Kafka está al tanto de que el nombre puede ser origen de un lenguaje, pero también final. En él laten por igual la posibilidad y la imposibilidad ${ }^{11}$. Por ello si se hubiese puesto en la tarea de crear una imagen del lenguaje verbal y escrito, sin duda lo habría hecho tal como el pintor de El Proceso desarrolla uno de sus cuadros ante José K: la figura de la diosa de la Justicia aparece representada con los atributos de la diosa de la Victoria; sin embargo en la pintura no se trata de ninguna de ellas pues lo que ambas encubren es la efigie resplandeciente de la de la diosa de la Caza. E lenguaje como cazador y la identidad como herida son un motivo recurrente de la obra de Kafka. En dos de sus relatos de animales y humanos que transforman su condición original, el contenido de la revelación asumido a contrapelo, crea los efectos más siniestros y humorísticos.

Pedro el Rojo, el simio que narra el Informe para una academia, ganó su nombre tal como él lo relata, por la cicatriz que dejaron en su rostro los traficantes de animales que lo capturaron. Por lo demás, su aprendizaje de la lengua humana no se debe a otra causa que a un intento por encontrar una salida de la jaula en la que se hallaba, una vez que la posibilidad de libertad había sido abolida. En La Metamorfosis, el punto macabro de la narración en el que la comedia y la tragedia se dan encuentro, este motivo del nombre que apresa y aniquila vuelve a aparecer. Luego de que la hermana, en compañía de la madre, desocupa la habitación de Gregorio por creer que en su nueva condición animal necesita mayor espacio y puede renunciar a toda costumbre humana, éste decide defenderse. Por eso sale de su habitación para aclarar lo que cree ha sido un malentendido, con la sorpresa de que su padre, por sentirse amenazado ante la presencia de tan enorme insecto, lo persigue (en cámara lenta) y luego lo bombardea con manzanas hasta clavarle una en el costado. Esa manzana nefasta, cuya herida que (a pesar de cicatrizar) lleva lentamente a Gregorio a la inmovilidad y a la muerte, también es la causa de su feliz reingreso en la familia (la rememoración de su nombre):

\footnotetext{
"Aquella grave herida que tardó más de un mes en curar -nadie se atrevió a quitarle la manzana, que quedó, pues, incrustada en su carne como testimonio ostensible de lo
ocurrido- pareció recordar, incluso al padre, que Gregorio, incrustada en su carne como testimonio ostensible de lo
ocurrido- pareció recordar, incluso al padre, que Gregorio,
} 
pese a su aspecto repulsivo actual, era un miembro de la familia, a quien no se debía tratar como un enemigo, sino, por el contrario, con la máxima consideración, y que era un elemental deber de la familia sobreponerse a la repugnancia y resignarse" (Kafka, 1985: 29).

Estos ejemplos ilustran el argumento de Benjamin al afirmar que esa tradición que le llegaba a Kafka vacía de su contenido fue la fuerza más potente que el escritor dispuso para confrontarse al mundo moderno al que pertenecía. Por eso lo dibuja como a alguien que se esfuerza en escuchar el pasado y a quien sólo le llegan susurros y ruidos, de los que sin embargo se apropia para confrontarse a un mundo que se le impone y que no puede ver porque, como el Angelus Novus de Klee (o el ángel de la historia de Benjamin) ha decidido darle la espalda ${ }^{12}$ y ya no puede girarse de nuevo. Para el filósofo, lo que había heredado el escritor era la hagadah de la tradición (el elemento narrativo y literario que le sirvió al judaísmo para transmitir la doctrina) sin su complemento, la halacha, (es decir, la doctrina misma) que, por cierto, había perdido sentido y valor: "No hay una doctrina que aprender ni un saber que pudiera conservarse" (Benjamin, 1980: 206) le dice Benjamin a Scholem en su carta del 12 de junio de 1938 refiriéndose al entorno social de Kafka. Se podria afirmar que algo similar consideró sobre su propia situación. A pesar de haber tenido también experiencias místicas (en el mismo sentido que las de Kafka, claro está) y puesto en movimiento categorias religiosas para desplegar su interpretación de las mismas (el ejemplo más claro es su teoría Sobre el lenguaje en general y sobre el lenguaje de los humanos) Benjamin no pudo dejar de reconocer una enfermedad en la tradición, que la obra de Kafka, tal como lo afirma en su carta a Scholem, no dejaba de reconfirmar.

\section{EXPERIENCIA Y ENFERMEDAD DE LA TRADICIÓN}

Benjamin rastreó esa enfermedad y la encontró en la incapacidad de narrar y legar de la que se había visto presa la experiencia. Recogiendo párrafos casi textuales de $E x-$ periencia y pobreza, Benjamin vuelve a abordar el tema del valor que había perdido la tradición oral en su ensayo El narrador. En esta oportunidad critica una vez más sus argumentos anteriores (tal como en Experiencia y pobreza lo habia hecho con respecto a su primer texto, Experiencia) pues ya no entiende esa crisis de la comunicación verbal como un resultado de la modernidad o una manifestación de decadencia, noción tan en boga en su tiempo. Por el contrario, asume que se trata de un fenómeno social de larga duración que emergía a medida que el aspecto épico de la verdad (la sabiduría) se había ido extinguiendo lentamente. Para Benjamin, el aspecto épico (popular) de la verdad existió mientras ésta se había transmitido en el habla; es decir, cuando gozaba de un lugar en la palabra viva; progresivamente las "fuerzas productivas históricas seculares" (Benjamin, 1971: 115) la habian desplazado a otros campos del saber, enajenándola lentamente del habla y de las costumbres. ¿Cuál es esa verdad que mantenía viva la tradición y que hacía del arte de narrar la forma artesanal de la comunicación? La muerte. Para Benjamin "... es la sanción de todo lo que el narrador puede referir y ella es quien le presta autoridad" (ibíd.: 121). Tal motivo hacía que en la figura del moribundo se concentraran los rasgos esenciales del narrador: "Pero es ante nada en el moribundo que, no sólo el saber y la sabiduria del hombre adquieren una forma transmisible, sino sobre todo su vida vivida, y ése es el material del que nacen las historias" (ibid.).

En su ensayo El narrador Benjamin reconoce que en el ocaso de la Edad Media el debilitamiento de la religiosidad, y con él, una atrofia en la idea de eternidad, habian dispuesto nuevas condiciones: "Desde siempre, el concepto de eternidad tuvo en la muerte su fuente principal. Por consiguiente el desvanecimiento de este concepto, habrá que concluir, tiene que haber cambiado el rostro de la muerte. Resulta que este cambio es el mismo que disminuyó en tal medida la comunicabilidad de la experiencia, que trajo aparejado el fin del arte de narrar (ibíd.: 120)". Cuando morir era un proceso público y ejemplar, anota Benjamin, la figura del narrador era solemne y la palabra que se decía de boca a oído pasaba de los viejos a los jóvenes cargada de valor. El lecho del moribundo se transformaba en trono, tal como lo muestra la iconografía medieval, y a su alrededor se asomaba "apretadamente el pueblo a través de las puertas abiertas de par en par" (ibíd.: 121) de la casa que recibía la muerte. Sin embargo tal como lo afirma Benjamin, la gestación de la modernidad (y su posterior expansión con el desarrollo de la burguesía) había desprovisto de su omnipresencia y plasticidad la conciencia colectiva del morir. Los estados modernos, con su despliegue de dispositivos higiénicos y sociales, emprendieron el diseño de espacios para residentes de la eternidad, que en el "ocaso de sus 
vidas eran depositados por sus herederos en sanatorios y hospitales" (ibíd.) Siguiendo a Benjamin "... morir, en el curso de los tiempos modernos, es algo que se empuja cada vez más lejos del mundo perceptible" (ibíd.).

Sin duda Kafka también intuyó la fuerza de la imagen del moribundo que le heredaba la tradición. Por eso la eligió, no sólo para recrear a sus personajes, sino también para fabricarse su propio autorretrato; en las cronologías del escritor es emblemática la imagen del momento en que por primera vez escupe sangre (1917); hasta en las más simples reseñas biográficas aparece consignada esta anécdota que a fuerza de repetición terminó por convertirse en gran acontecimiento. El mismo Kafka se encargó de mitificar este suceso en su Carta al padre, con una descripción entre trágica y cómica: "Finalmente, bajo los esfuerzos sobrehumanos que acompañaron mis deseos de casarme la sangre se me salió de los pulmones" (Kafka, 1995: 70). De hecho, tal como lo rescatará Blanchot a partir de unas notas del diario del escritor, en todo lo amplio de la obra kafkiana se dibuja una muerte contenta: "Olvidé agregar, y luego lo omití a propósito, que lo mejor que he escrito se basa en esa aptitud para morir contento" (Blanchot, 1993: 172).

Sin embargo en las narraciones de Kafka la muerte aparece incompleta. A Joseph $\mathrm{K}$ le sobrevive la vergüenza, a Gregorio Samsa, su hermana en el pleno despertar de la sexualidad. En La Condena, luego del suicido del joven Bendeman, se describe una loca circulación de tráfico que le hacia pensar a Kafka en una fuerte eyaculación. Uno de sus personajes más conmovedores, el cazador Gracchus, está muerto, pero el piloto que lo llevaba al más allá confundió el camino y ahora surca las aguas terrenales: "El error fundamental de mi muerte resuena sarcásticamente en mi barca" (Kafka, 2001: 233). Esta presencia amenazante de la muerte conjugada con la tensión frente a la imposibilidad de morir es lo que Benjamin denominó como lo verdaderamente genial en Kafka, y a la vez como el signo de su fracaso histórico. Pues si bien en su obra se prueba algo nuevo por entero -"abandonar la verdad para atenerse a su transmisibilidad" (Benjamin, 1980: 207)- ese intento que debía anularla por completo, la hace brillar de manera resplandeciente. Kafka es el moribundo que ha perdido la autoridad de narrar porque su muerte no llega; una caricatura profunda del sujeto moderno (y posmoderno). A propósito, anota Blanchot robándole unas palabras a Kafka:
"La muerte está ante nosotros más o menos como el cuadro La Batalla de Alejandro en la pared de un aula. Desde esta vida, para nosotros se trata de oscurecer o incluso de borrar el cuadro por medio de nuestros actos. La obra de Kafka es ese cuadro que es la muerte y también es el acto de hacerla oscura y de borrarla. Pero, como la muerte, esa obra no pudo oscurecerse $y$, por el contrario, brilla admirablemente con ese vano esfuerzo que ha realizado para extinguirse (Blanchot, 1993: 95)".

El fracaso histórico de Kafka es el mejor testimonio de la equivocación de una sociedad que hasta hoy pone todos sus empeños en borrar y desnaturalizar la muerte. Ese no ocuparse de ella coincide con su transformación en un espectáculo ajeno con el que el ciudadano se entretiene y un índice trágico del que se informa. Haber puesto toda su jurisdicción en manos de una cultura que sólo la piensa como enfermedad o cura, fue lo que le devolvió y aún le devuelve con interés compuesto esa jugada a la experiencia. En el afán de proscribirla de sus espacios y sus ritos, en la ansiedad feroz de reforzar los sistemas de defensa (tanto médico, como militar) la humanidad civilizada desplaza esas fuerzas aniquiladoras a otros ámbitos, en los que sin embargo no se puede conjurar el peligro: "Esa ligereza del Occidente con la ley, su ausencia a la crueldad. Todo lo que quiere saber, de la crueldad, es poco más o menos la receta del cocinero: para hacer una tortilla, hay que romper algunos huevos" (Lyotard, 1997: 47). Sin embargo, tal como lo demostró el siglo XX, esa ligereza es sólo un lado de la cultura, cuyo extremo opuesto es la técnica moderna, que aún hoy representa la más sofisticada amenaza: "La medida del asunto la da que fuese necesario apelar a nada menos que a las fuerzas de esa tradición, si es que alguien (que se Ilamó Franz Kafka) quería confrontarse con la realidad que, en cuanto nuestra, se proyecta teóricamente por ejemplo en la física moderna y prácticamente en la técnica bélica" (Benjamin, 1980: 206).

Una vez llegado a este punto de su reflexión, Benjamin se pregunta en su carta. ¿Qué experiencia es posible heredar de esta obra? Sin duda ella no puede revelar ese lado épico de la verdad que había acompañado a la tradición. "Por eso Kafka no habla de sabiduría. Sólo le quedan los productos de su ruina. Y estos dos son" (ibíd.: 207): el rumor de las cosas verdaderas y la locura. Benjamin desechó el primero por considerarlo un parloteo inútil "(una especie de periódico de cuchicheos teológicos en el que se trata de lo 
desacreditado y lo obsoleto)" (ibíd.), y consideró al segundo como la herencia más valiosa. Para el filósofo la locura conservaba "el garbo y la tranquilidad que se le escapaban al rumor" (ibíd.). Sin embargo, no se debe pasar por alto que ésta es, ante todo, una condición de incomunicabilidad. Por eso Benjamin en este punto llegaba a un callejón sin salida, que de hecho lo alejaba de su cometido inicial: pensar la experiencia. Kafka, en su lugar, elige el rumor (incluso en su grado de incomprensión más extremo, el ruido) porque es en él, y no en la locura, donde encuentra los vacíos de sentido que habían conformado su escritura. Es cierto que en sus últimos relatos el ruido ocupa un lugar determinante. Parece como si se tratara de eliminar con él todo significado común posible (un intento de acceder por medio de él a la locura). Sin embargo, las narraciones ganan, y el ruido revela su origen en una de las nociones más ricas en significado de la obra de Kafka.

\section{DeVOlVer la tRadición a la eXPeRIencia: POR UNA POÉTICA DEL MALENTENDIDO}

En Kafka no hay una poética de la locura desarrollada de manera tan clara como en Don Quijote o en Rimbaud. Después de todo La Metamorfosis sigue siendo una lectura que se recomienda (¿quién lo hace?) a los jóvenes y se lee en instituciones educativas. Parece que el escritor fue consciente de que una apología de la locura, tal como se desarrolló en forma de consigna en movimientos como el surrealismo, era una operación inútil políticamente. En el siglo XX y los años que han transcurrido de éste, la locura ha sido atrapada y puesto al servicio del poder en sus dos extremos. Focuault la hizo visible como índice y posibilidad de patologización y medicalización (control) del sujeto en la sociedad de masas, y la historia política ha sido la prueba de que en procesos de arduas transformaciones sociales y económicas, su rostro (el de la locura) ha aparecido encarnado en los tiranos y los revolucionarios, sin que por esto se halla hecho accesible a la multitud como herramienta de liberación.

En su lugar, Kafka dejó algo que se puede considerar más pueril, pero que sin duda, está lleno de fuerza: una poética del malentendido. En parábolas cortas como Un viejo manuscrito pero también en las escenas más dramáticas de sus relatos y en el núcleo que desata los argumentos de sus novelas, el malentendido juega un papel fundamental.
¿Quién y por qué ha hecho una acusación a José $K$, para que una mañana irrumpan en su habitación dos hombres que además de comunicarle que un proceso ha sido abierto en su contra, le roben su ropa interior y se coman su desayuno? ¿Quién ha llamado a $\mathrm{K}$ a trabajar como agrimensor para el castillo, cuando ni siquiera le ha sido otorgado el permiso de vivir en la aldea que lo rodea? "La salvación de la patria depende de nosotros, artesanos y comerciantes; pero no estamos preparados para semejante empresa; tampoco nos hemos jactado nunca de poder afrontarla. Hay algún malentendido, y ese malentendido será nuestra perdición" (Kafka, 1985: p. 66).

En las escenas donde las situaciones se dislocan, algo que ocurre con bastante frecuencia en la escritura de Kafka, se despliega el humor que ha permitido a su obra sobrevivir con fuerza hasta hoy. El proceso es la muestra más clara del malentendido convertido en la ley de la narración. Una vez entregado a su caso, José $K$ no puede menos que asombrarse con todo lo que ocurre. Sin lógica previa, los espacios truecan en un instante su disposición y uso; la habitación de la señorita Burstner, la vecina de José K, se convierte en salón de interrogatorios. El cuarto trastero de la oficina, en celda de torturas. El juzgado se monta como un teatro absurdo en el desván de un edificio en un barrio marginal. Asimismo los personajes varian sus actitudes inesperadamente. El abogado, que en un momento parecía muy enfermo, se pone en pie atléticamente. La audiencia que ovaciona y aplaude la intervención de José K, luego le da la espalda y cuchichea burlonamente. Él mismo, un instante después de besar tímidamente a la señorita Burstner por primera vez, le lame "toda la cara, igual que un animal sediento pasa la lengua por toda la superficie del agua al fin hallada..." (Kafka, 1998: 35).

En el humor de Kafka no reposa solamente la risa -aunque sea ella su efecto principal- sino también toda la enseñanza política que pudo legar. En medio de la situación amenazante que se vivía en Europa de manera cada vez más evidente para los judios, Benjamin intuyó esa dirección. Tal como se ha mencionado en el inicio de este ensayo, entre las últimas cartas que envió a Scholem, le confiesa esto: "Cada vez en mayor medida creo que lo esencial en Kafka es el humor. Naturalmente no era un humorista. Era más bien un hombre cuyo destino fue tropezar con personas que habian hecho del humor su profesión: con payasos" (Scholem, Benjamin, 1987: 268). Esta declaración tragicó- 
mica le permitió volver a mirar el enigmático papel que en la vida de Kafka representaba Brod, a quien le había legado su obra para que la echara al fuego, con tal mala suerte de que éste en vez de cumplir su cometido, la había publicado envuelta en una falsa aura de santidad que por cierto, para Benjamin, era una montaña de estiércol. Por eso reconoce en la pareja Kafka Brod, no al místico y profeta, sino al gordo y el flaco: "Kafka, en el papel de Laurel, sentía la pesada obligación de buscarse su Hardy y ése era Brod" (ibíd.).

En El autor como productor, uno de los ensayos más combativos de Benjamin, el humor sale a flote como el último y casi más eficaz de los recursos para una práctica militante de la libertad: "advirtamos no más que marginalmente que no hay mejor punto de arranque para el pensamiento que la risa. Y una conmoción del diafragma ofrece casi siempre mejores perspectivas al pensamiento que la conmoción del alma" (Benjamin, 1995: 132). Cuando el malentendido surge como la ley de la narración y la experiencia, no queda otra opción diferente a la sospecha que ríe. Kafka nos hace reparar en que los gestos de terror pueden ser interpretados como acciones violentas, tal como sucede con los enfrentamientos (encuentros) entre padre e hijo en La Metamorfosis (eso sin contar que el aparente combate que se desarrolla en este relato es una farsa ya que para ambas partes terror y violencia se han dislocado por completo de su lugar). Por eso admitir el malentendido implica, tal como lo hizo Kafka, abrir una distancia y saber estar en falso frente a la identidad, la lengua y el poder. Sólo así es posible resignificar la tradición, sólo así es posible jugar con la cultura. Sin embargo no sobra reconocer que esta dimensión de la experiencia tampoco es dominable. De hecho Kafka anota con asombro en su diario cómo, con bastante sistematización, de esa comedia pudo surgir una realidad (Bataille). El malentendido nos sobrepasa; es una fuerza que atraviesa la historia y la cultura, y a ella precisamente se debe gran parte de su dinamismo. La historia que Scholem refiere de la tumba de Benjamin, tal como si fuera un relato kafkiano, es una anécdota adecuada para cerrar este ensayo:

\footnotetext{
"Estas fotografías que tengo ante mi indican con claridad que esta tumba absolutamente solitaria, del todo aislada de las auténticas sepulturas, es una invención de los guardas del cementerio, que, al ser preguntados varias veces por ella, se quisieron asegurar algunas propinas. También algunos visitantes que estuvieron allí me confirmaron la misma impresión. Ciertamente, el lugar es bello; la tumba es apócrifa" (Scholem, Benjamin, 1987: 296).
}

\section{NOTAS}

1 Franz Kafka (1883-1924), Walter Benjamin (1892-1940).

2 Benjamin tuvo que publicar algunos de sus trabajos en Die Frankurten Zeitung utilizando otro nombre que no revelara su ascendencia judía.

3 Se pueden dar varios ejemplos de esto. Uno de ellos tiene que ver con la teoría del lenguaje de Benjamin. En ella, el filósofo desarrolla una reflexión sobre el origen del lenguaje humano a partir del nombre: "El nombre, como patrimonio del lenguaje humano, asegura entonces que el lenguaje es la entidad espiritual por excelencia del hombre" (Benjamin, 1971: 63). En la obra de Kafka, el nombre, antes que una entidad espiritual, representa una fuerza aniquiladora. En varios de sus relatos y en sus novelas, el nombre está íntimamente ligado a una condena y una herida.

4 A propósito de este ensayo le escribe Scholem a Benjamin: "El primer capítulo es incuestionablemente el mejor en cuanto a la exposición, francamente acertada; después hay en parte demasiadas citas y en parte poco trabajo de interpretación" (Benjamin, Scholem, 1987: 154).

5 El término acción eficaz es tomado de George Bataille quien en su ensayo sobre Kafka en el libro La literatura y el mal lo utiliza para enfrentarlo al imperativo del deseo inmediato, que no busca metas a largo plazo, sino la satisfacción instantánea y sin cálculo.
Recibido: 16 de marzo de 2009

Aceptado: 23 de abril de 2009 
6 "En suma no es Edipo el que produce la neurosis, es la neurosis -es decir, el deseo ya sometido y que busca comunicar su propia sumisión- la que produce a Edipo. Edipo, valor de cambio de la neurosis. A la inversa, amplificar y agrandar a Edipo, exagerarlo, usarlo perversa o paranoicamente, es una manera de salir de la sumisión, levantar la cabeza y ver por encima del hombro del padre..." (Deleuze, 1978: 21).

$7 \mathrm{El}$ interieur (interior) es una noción que Benjamin utiliza para hacer referencia al espacio privado -tanto material como psicológico- del burgués del siglo XIX.

8 Kafka, de Max Brod, fue la primera biografía que se escribió de Kafka y quizás la más difundida inicialmente.

9 "Cuando Brod dice de él [de Kafka] que estuvo en la línea de un Buber, busca la mariposa en una red sobre la que revolotea y arroja su sombra. La 'interpretación que Ilamariamos judío-realista' de El Castillo malversa los repulsivos y terroríficos rasgos, con los que Kafka dota al mundo de arriba, en favor de una hermenéutica edificante que precisamente, debiera al sionista resultarle sospechosa" (Benjamin, 1980: 201).

10 "... los estudiosos de la Cábala necesariamente se enfrentan a la problemática de mil años de tradición oral. Todo el medievalismo judio se vuelve un vasto laberinto en que las ideas distintivas de la Cábala se inventaron, revisaron y transmitieron en un área que abarcaba desde Babilonia hasta Polonia. En estas amplias extensiones de espacio y de tiempo, hasta Scholem se confunde, ya que la esencia misma de la tradición oral es vencer sobre toda la erudición histórica y crítica" (Bloom et al., 1999: 204).
11 Tal es la razón para que la fuerza poética no aparezca en su obra encarnada en el nombre, sino en el lenguaje del gesto. "Como el Greco, Kafka abre con cada gesto el cielo, pero también como en el Greco -que era el santo patrono de los expresionistas-, el elemento decisivo, el centro de la cuestión, sigue siendo en él el gesto" (Benjamin, 1971: 121).

12 Benjamin relaciona en su carta a Kafka con Klee: "Kafka vive en un mundo complementario (y en ello está emparentado con Klee, cuya obra se alza en la pintura tan esencialmente aislada como la de Kafka en la literatura)" (Benjamin, 1980: 206). Esta relación se puede comprender mejor a la luz de la novena tesis de la filosofía de la historia que desarrolla Benjamin a partir del Angelus Novus, un cuadro de Klee, para recrear la figura del ángel de la historia. La imagen que dibuja Benjamin a partir de esta pintura es la de un ángel volteado hacia el pasado, observando las ruinas que deja tras de sí la historia mientras un huracán (el progreso) lo empuja de espaldas al futuro.

\section{BIBLIOGRAFÍA}

Bataille, G. (1977): La literatura y el mal: Emily Bronte, Baudelaire, Michelet, Blake, Sade, Proust, Kafka, Genet, Madrid, Taurus Ediciones, p. 116.

Benjamin, W. (1989): Escritos, la literatura infantil, los niños y los jóvenes, Buenos Aires Ediciones Nueva Visión, pp. 41, 42, 43.

Benjamin, W. (1974): Discursos interrumpidos I, Madrid, Taurus Ediciones, pp. 167, 168, 170, 171.

Benjamin, W. (1980): Iluminaciones I, Imaginación y sociedad, Madrid, Taurus Ediciones, pp. 206, 207, 208, 221.
Benjamin, W. (1971): Sobre el programa de la filosofía futura y otros ensayos, Montevideo, Monte Ávila Editores, pp. 63, 120, 121, 44.

Blanchot, M. (1993): De Kafka a Kafka, México, D.F., Fondo de Cultura Económica, pp. 95, 172.

Benjamin, Walter (1995): Iluminaciones III, Madrid, Ed. Taurus, p. 132.

Bloom et al. (1999): Cábala y deconstrucción, México, D.F., Azul Editorial, pp. 204, 222.

Deleuze, G. y Guattari, F. (1978): Kafka: por una literatura menor, México D.F., Ediciones Era, pp. 21, 23.

Kafka, F. (1995): Carta al padre, Bogotá, Panamericana editorial, pp. 21, 70.

Kafka, F. (2001): Cuentos completos, Madrid, Valdemar editores, pp. 233, 354.

Kafka F. (1985): La metamorfosis y otros relatos, Bogotá, Editorial Oveja Negra, pp. 29, 66.

Kafka F. (1998): El proceso, Madrid, Alianza Editorial, p. 35.

Lyotard, J. F. (1997): Lecturas de infancia: Joyce, Kafka, Sartre, Válery, Freud, Buenos Aires Eudeba, p. 47.

Nordau, Max, Arantegui, J. L. (Prólogo) (1999): Fin de siglo, Jaén, Del Lunar, p. 7.

Robert, M. (1993): Franz Kafka o la soledad, México D.F., Fondo de Cultura Económica, pp. 13, 32, 59, 60, 78, 89.

Scholem, G. (2004): Los nombres secretos de Walter Benjamin, Madrid, Editorial Trotta S.A., p. 25.

Scholem, G. y Benjamin, W. (1987): Correspondencia 1933-1940, Madrid, Taurus Ediciones, pp. 153, 160, 161, 268, 296.

Scholem, G. (1998): Conceptos básicos del judaísmo: Dios, creación, revelación, tradición, salvación, Valladolid, Editorial Trotta, p. 88.

Scholem, G. (2005): La Cábala y su simbolismo, Buenos Aires, Siglo XXI Editores, pp. 8, 13. 